\title{
The Method and Its Application of Project Management Modeling in Whole Life Cycle
}

\author{
Huan Zhao \\ Education Technology Center \\ Beijing International studies University \\ Beijing, China \\ zhaohuan@bisu.edu.cn
}

\author{
Xi Chen \\ Education Technology Center \\ Capital University of Economics and Business \\ Beijing, China \\ chenxi@cueb.edu.cn
}

\begin{abstract}
Project management is the application of knowledge, skills, tools and techniques to project activities, in order to meet the project requirements. As long as the project requirements become more complex and volatile in the university, the ability to optimize and integrate costs, schedule, effort and benefits become the most important. Therefore, how to control the project's whole life cycle in efficient and effective ways has become a critical issue for information engineers in universities. To resolve this problem, this paper extends an information system management model to the whole life cycle of project, which can manage whole procedure from feasibility analysis to performance review, and make sure implementation of information system project in universities.
\end{abstract}

Keywords-Management Model; Life Cycle; Analysis; Project Management; Information System;

\section{INTRODUCTION}

Like all things around the world, IT project in university also has its own life cycle, which includes application, tender, implementation and acceptance etc. With the continually-increasing capability of information technology and scale of application, the complexity of project is also continually increasing, and has manifested itself as one of the key factors that limit the significant improvement of project quality and productivity. Therefore, researchers focus on some project management tools as well as pay more attention to strategies and methods of project management. Therefore, this paper proposes an information system project management model based on the whole life cycle, which can provide powerful support for theory and technology of project management [1].

Life cycle theory is a methodology in the intersecting field between economy, management and information technology, which can combine strategy target of university with information theory. To apply this theory, it will not only increase efficiency and benefit of information system and promote pluralistic education, but also will boost the innovation of scientific methods and techniques. In this paper [2], researchers propose a project management architecture centric model approach for information system, which spans over all phases of project lifecycle, including the analysis, design, implementation, deployment, maintenance and evolution of management, that are used to model, organize and manage "disordered" project resources.

\section{RESEARCH OF INFORMATION SYSTEM PROJECT MANAGEMENT MODEL BASED ON WHOLE LIFE CYCLE}

\section{A. Methodology oflife cycle project management}

A project life cycle is the series of phases that a project passes through from its initiation to its closure. The phases can be broken down by functional or partial objectives, intermediate results or deliverables, specific milestones. The project life cycle can be determined or shaped by the unique aspects of the organization, industry, or technology employed [3].

1) Fully plan-driven life cycle is a method in which the project scope, and the time and cost required to deliver that scope, are determined as early in the project life cycle as practically possible. When the project is initiated, this method focus on defining the overall scope for the product and project, develop a plan to deliver the product, and then proceed through phases to execute the plan within that scope. This method is generally preferred when there is a substantial base of practice, and requirements and scope are easy to define in advance.

2) Iterative and incremental life cycle is a method in which project phases intentionally repeat one or more project activities. Iterations develop the product through a series of repeated cycles, while increments successively add to the functionality of the project. A high-level vision will be developed for the overall undertaking [4], and then the detailed scope is elaborated one iteration. Often the planning for the next iteration is carried out as work progresses on the current iteration's scope and deliverables. This method is generally preferred when objectives and scope of project are always changed, and the complexity of a project is needed to reduce. Large and complex projects are frequently executed in an iterative way.

3) Change-driven life cycle is a method in which project phases intended to respond to high levels of change and iterations are more rapid than iterative and incremental life cycle, and fixed in time and cost. This method is generally preferred when dealing with a rapid ly changing environment, 
when requirements and scope are difficult to define in advance.

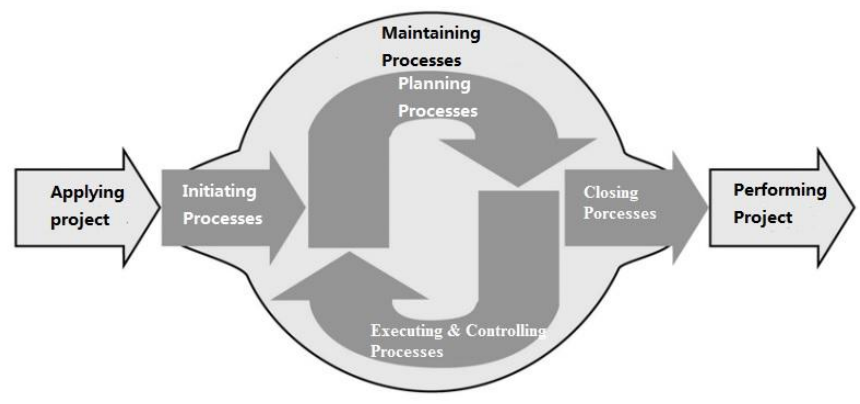

Figure 1. Project life cycle flow.

\section{B. Analysis of information system project management model}

IT project is throughout the ideological of system engineering[5]. As a complete system, a project can be distributed into a lot of units by system theory, whether one of the units is ignored will lead to failure of the project. All projects can be mapped to the generic life cycle structure as Initiating, Planning, Executing and Controlling, Closing and Maintaining. The government provides most of funding in IT project of university that is a public service institution. Therefore, before the project initiating and after the project closing, there are two more units such as applying and performing [6]. As shown in Fig. 1.

1) Application Process: the review and approval of a typical project usually occurs in some distinct phases: design report, specifications and documentation for review, budget of the project, feasibility report etc.

2) Initiating Process: this process performed to define a new project or a new phase of an existing project by obtaining authorization to start the project.

3) Planning Process: this process required to establish the scope of the project, refine the objectives, and define the course of action required to attain the objectives that the project was undertaken to achieve.

4) Executing and Controlling Process: this process performed to complete the work defined in the project management plan to satisfy the project specifications, identify any areas in which changes to the plan are required, and initiate the corresponding changes.

5) Closing Process: this process performed to finalize all activities across all process to formally close the project or phase.

6) Monitoring and Maintaining Process: this process required to track, review, and regulate the progress and performance of the project.

7) Performance Process: this process is measured and analyzed at regular intervals, appropriate events, or exception conditions to identify variances from the project management plan.

\section{DESIGN OF INFORMATION SYSTEM PROJECT MANAGEMENT MODEL}

Project management is the application of knowledge, skills, tools and techniques to project activities to meet the project requirements. For the effective management of the project, each process is needed to be appropriately aligned and connected with the other processes to facilitate coordination, which is characterized by its inputs, the tools and techniques that can be applied, and the resulting outputs.

Throughout the life cycle of the project, a significant amount of data and information is collected, analyzed, transformed and is shared within the project team. The collected data are analyzed in context, and aggregated and transformed to become project information during various controlling processes, and then the information should be stored and distributed as reports in various formats.

Based on the aforementioned analysis, researchers propose an architecture centric project management method to control structural complexity in the whole lifecycle and to improve the efficiency and quality of project management. This method unifies the core artifacts in different management lifecycle phases into different kinds of architecture models, as shown in Fig. 2. Afterwards, the core activities of project management are performed as the continual refinement and transformation to these different kinds of architecture models.

1) Application model must complete the feasibility study of the project, and scope the requirements and performances. Information projects should be concluded in accordance with the procedure prescribed by the government and in compliance with the government - approved documents such as the policies and regulations, etc.

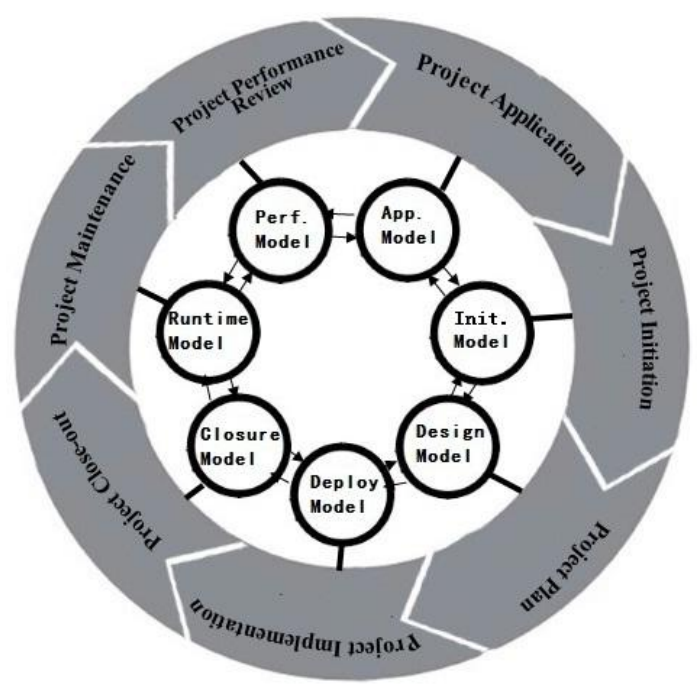

Figure 2. Project management model in whole life cycle.

2) When the project is initiated, the project team will focus on defining the overall scope for project, develop a plan to deliver the product, and then proceed through phases to execute the plan within that scope. Inception conference 
was an important milestone during the project, which team leaders, engineers and other personnel have a certain understanding about this project through training and communication[7].

3) The design model consists of those processes performed to establish the total scope of the effort, define and refine the objectives, and develop the project management plan and the project documents that will be used to carry out the project, which all these plan and documents developed as outputs from the design model will explore all aspects of the scope, time, cost, quality, communications, human resources, risks, procurements, and stakeholder engagement.

4) The deploy model includes the following three aspects: a working group should responsible for project requirements analysis, schedule management, quality control, communication and project implementation, and archive all kinds of project management documents, monitor the implementation of software service and upgrades; the second is to strengthen the information system security[8]. According to national information system-level protection requirements, the working group should classify this project and plan and design the whole information systemsecurity architecture.

5) The closure model consists of those processes performed to conclude all activities across all project management process to formally complete the project, which is a whole assessment of project completion process, and the main contents include project management, project technical specifications, project financial performance and so on. Before the final acceptance, all kinds of project documentations should be collected and organized, and then examined by several experts.

6) The runtime model includes application maintenance plans, data maintenance plans, code maintenance plans, hardware maintenance plans and document maintenance plans [9]. It is a catchall term used to describe various forms of server maintenance required to keep a system running properly. It can describe system maintenance, which could mean that servers are being physically repaired, replaced, or moved.

7) With the continuous development of information technology, the returns on investment in information technology were increasingly concerned by government. Information technology project performance evaluation generally refers to assessment by other organizations or individuals. On the one hand, the performance data collected from various controlling processes, analyzed in context and integrated based on relationships across areas, on the other hand, the physical or electronic representation of work performance information compiled in project documents, intended to generate decisions or raise issues, actions, or awareness [10].

Project management models are usually presented as discrete processes with defined interfaces while, in practice, they overlap and interact in ways. They are linked by the outputs which are produced. They are seldom either discrete or one-time events and are overlapping activities that occur throughout the project. The output of one model generally becomes an input to another model or is a deliverable of the project, as shown in Fig. 3.

\section{IT Project Management Models}

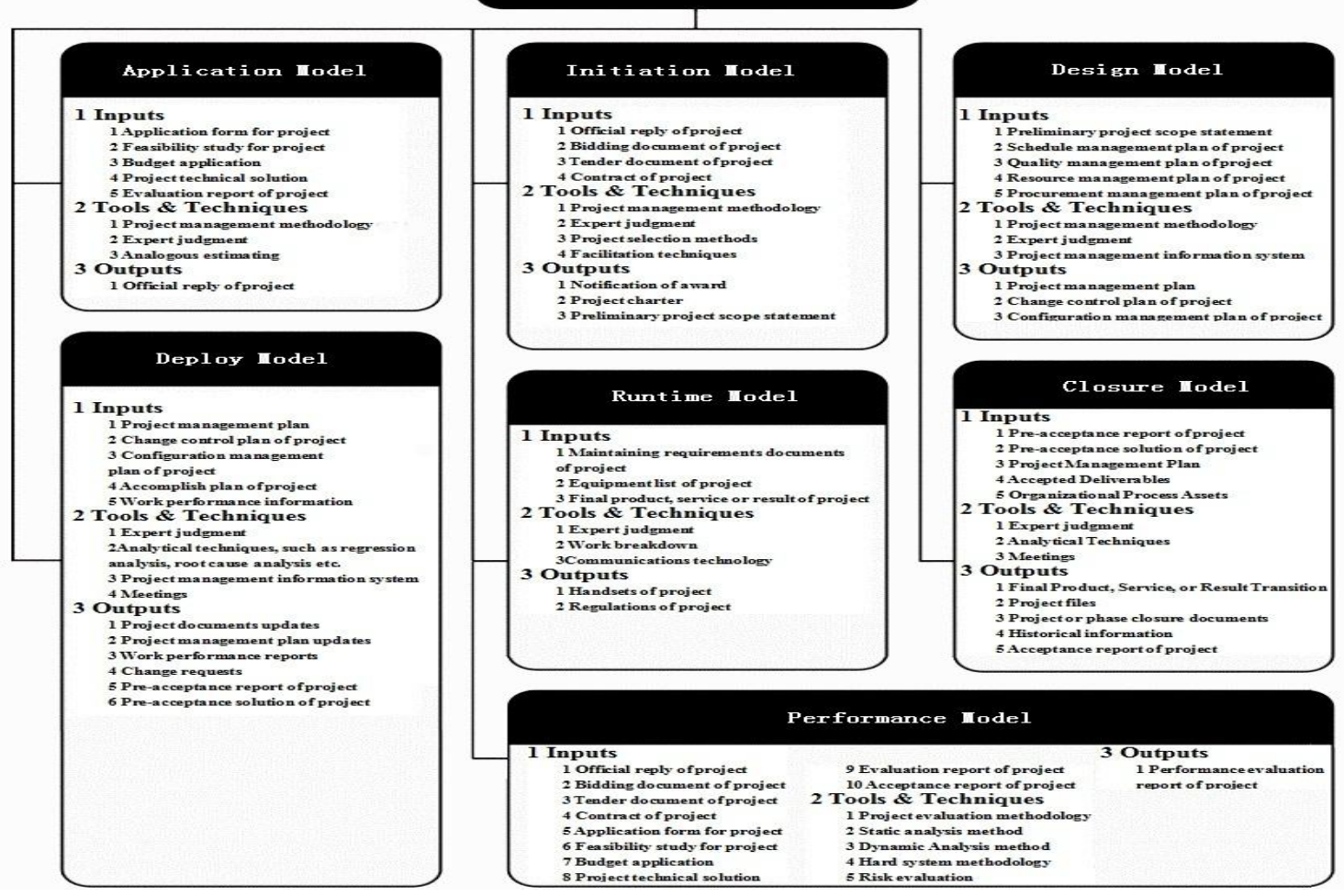

Figure 3. Project management model overview. 


\section{APPLICATION AND EFFECT OF INFORMATION SYSTEM PROJECT MANAGEMENT MODEL IN UNIVERSITY}

The life cycle management model were implemented in information projects that achieved very significant effect, which manage and control the processes of application, initiation, plan, deployment, closure, maintenance and performance, and strictly refine those processes and carry out these requirements inn every unit of each project.

Through applying for management model in the past four years (2011-2014), more than 70 information technology projects were managed and controlled, which reduced percent of budget reduction every year, largely promoted pass rate of mid-term inspection and finish rate of project, and increased the project performance evaluation excellence rate significantly, as shown in Fig. 4. The project percent of budget reduction shrink from $29.1 \%$ in 2011 to $6.9 \%$ in 2014 , and pass rate of mid-term inspection raised from $76.47 \%$ in 2011 (four projects is not passed from 17 projects) to $93.75 \%$ (one project is not passed from 16 projects) in 2014, finish rate of project increased from
$82.35 \%$ (three projects is not passed from 17 projects on schedule) in 2011 to $100 \%$ in 2014 and performance evaluation excellence rate(random check) raised from 0\%(four projects) in 2011 to 100\%(five projects) in 2014.

\section{CONCLUSIONS}

As the Information Technology keeps rapid and continuous development, the existing project management may confront more and more require ments and challenges. Typically, due to their static and close nature, the traditional management are not adequate and suited for the open, dynamic and ever-changing IT. In this paper, researchers introduce an architecture centric technical framework for project management, including a management model based autonomous entities and structured collaborations, and a method based on management architecture in the whole life cycle. Whatever, there are many open issues to be addressed, such as improving the automation of design for management model, incarnating cooperation among processes and phases, and so on.

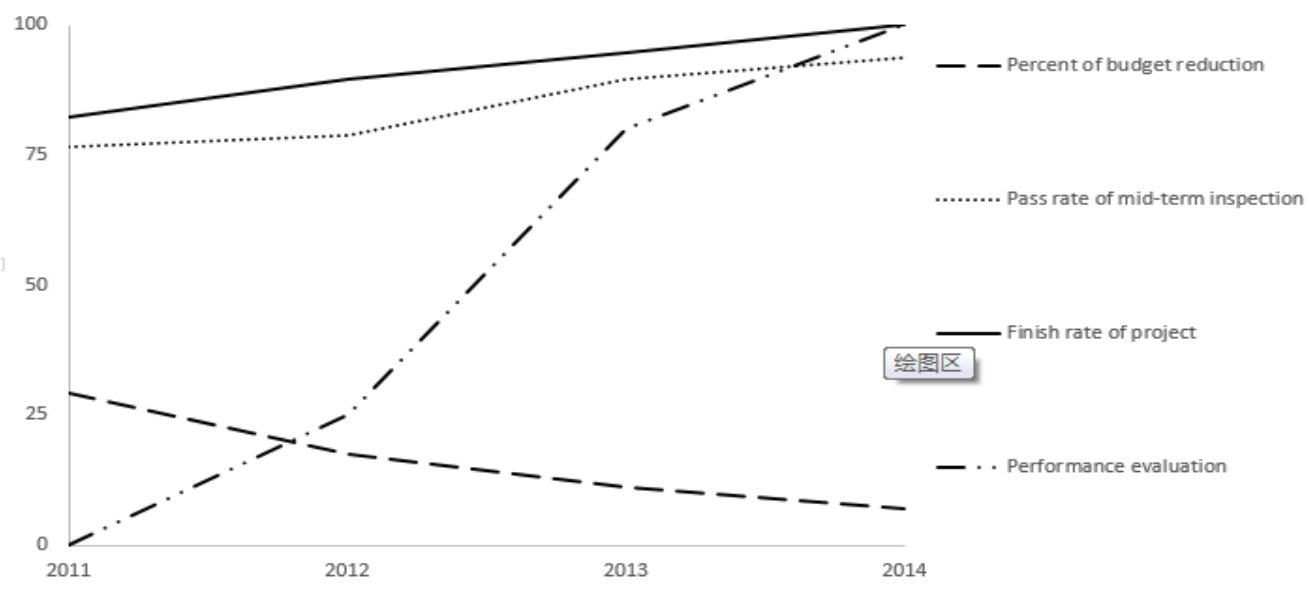

Figure 4. Comparison chart after applying model.

\section{REFERENCES}

[1] T. Mens, "On the complexity of soft ware systems," IEEE Computer, vol. 45, 2012, pp. 79-81

[2] W. Zhang, L. Yi, H. Zhao, et al. "Feature-oriented stigmergy-based collaborative requirements modeling: An exploratory approach for requirements elicitation and evolution based on web-enabled collective intelligence," Sci China Inf Sci, vol. 56, 2013, pp. 082108(18)

[3] Poject Management Institute. A guide to the project management body of knowledge, 4th ed. Newtown Square: Project Management Institute, 2009

[4] H Mei, G Huang, T Xie. "Internetware: A software paradigm for Internet computing," Computer, vol. 45, 2012, pp. 26-31
[5] H. Song, G. Huang, F. Chauvel, et al. "Supporting runtime soft ware architecture: A bidirectional-transformation based Approach," J Syst Softw, vol. 84, 2011, pp. 711-723

[6] X. P. Chen, G. Huang, Y. C. Sun, et al. "A software architecture Model supporting analysis and planning in self-adaptation," J Compute Res Dev, vol. 07, 2010, pp. 1156-1165

[7] Dai Yubiao, Ren Xueli, "Research on project critical chain based on Bayesian network," Computer Applications and Software, vol. 26(10), 2009, pp. 127-129

[8] Cui X F, Sun Y C, Mei H. A decision-centric software architecture design method. J Soft w, 2010, (06): 1196-1208

[9] Mei H, Wang Q X, Zhang L, et al. Software analysis: A road map. Chinese J Comput, 2009, 32: 1697-1710

[10] Meng S, Wang X, Zhang L, et al. A history-based matching approach to identication of framework evolution. In:Proceedings of 34th International Conference on Software Engineering (ICSE), 2012. 353-363. 